$$
\text { Corf-9505/2--301 }
$$

UCRL-JC-119208

PREPRINT

\title{
Wiggler Insertion of the PEP-II B-Factory LER
}

\author{
J. Heim \\ L. Bertolini \\ J. Dressler \\ O. Fackler \\ B. Hobson
}

\author{
M. Kendall \\ T. O'Connor \\ W. Stoeffl \\ T. Swan \\ A. Zholents \\ M. Zisman
}

This paper was prepared for submittal to the 1995 Particle Accelerator Conference \& International Conference on High-Energy Accelerators IEEE

Dallas, TX

May 1-5, 1995

\section{April 1995}

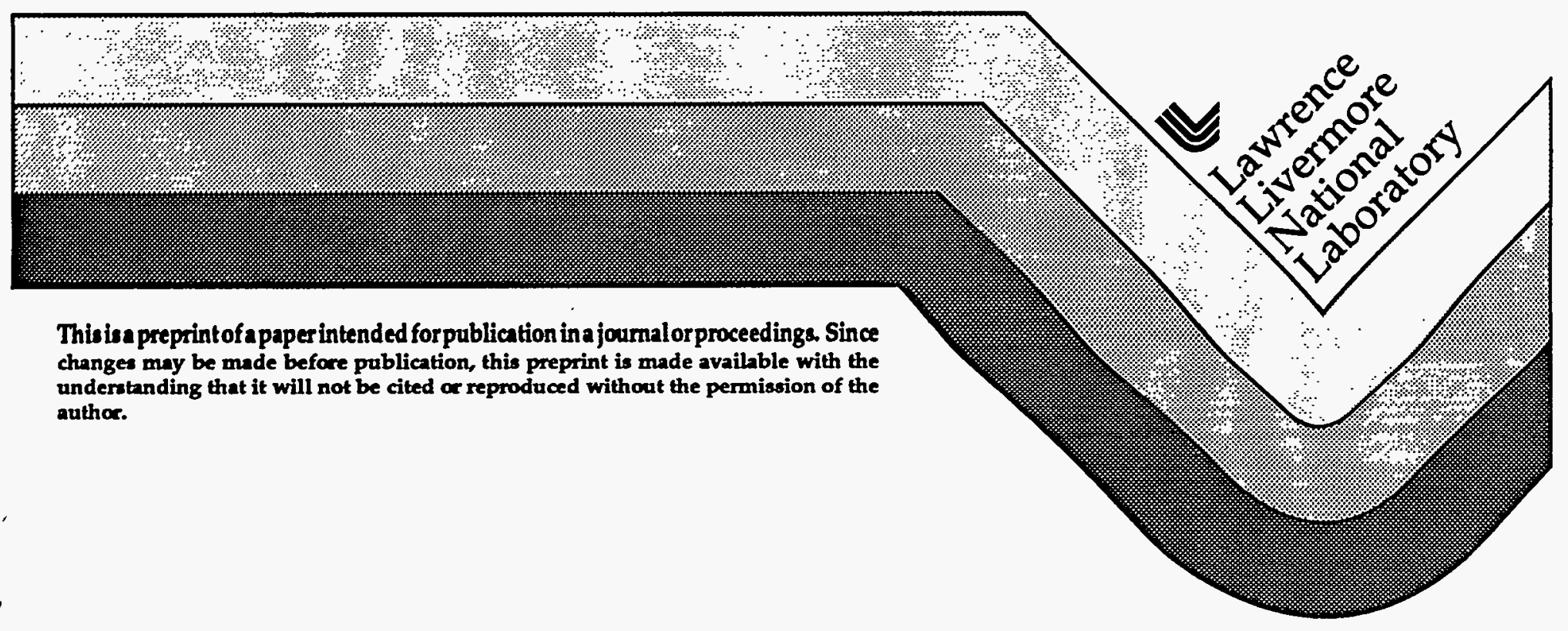




\section{DISCLAIMER}

This document was prepared as an account of work sponsored by an agency of the United States Government. Neither the United States Government nor the University of California nor any of their employees, makes any warranty, express or implied, or assumes any legal liability or responsibility for the accuracy, completeness, or usefulness of any information, apparatus, product, or process disclosed, or represents that its use would not infringe privately owned rights. Referenoe herein to any specific commercial product, process, or service by trade name, trademark, manufacturer, or otherwise, does not necessarily constitute or imply its endorsement, recommendation, or favoring by the United States Government or the University of California. The views and opinions of authors expressed herein do not necessarily state or reflect those of the United States Government or the University of California, and shall not be used for advertising or product endorsement purposes. 


\section{DISCLAIMER}

Portions of this document may be illegible in electronic image products. Images are produced from the best available original document. 


\title{
Wiggler Insertion of the PEP-II B-Factory LER
}

\author{
J. Heim, L. Bertolini, J. Dressler, O. Fackler, B. Hobson, M. Kendall, T. O'Connor, W. Stoeffl, T. Swan, \\ Lawrence Livermore National Laboratory
}

\author{
A. Zholents, M. Zisman, B-Factory Project and Center for Beam Physics, AFRD, LBL, Berkeley
}

\begin{abstract}
The Low Energy Ring (LER) of the PEP-II B Factory at SLAC employs two identical wiggler insertions for emittance control and extra damping with each insertion designed to absorb $400 \mathrm{~kW}$ of synchrotron radiation. The wiggler is a set of individual iron core dipoles designed to operate at 1.6 $\mathrm{T}$. The basic variant will include nine 0.4-m length magnets and two 0.2-m length magnets. A copper vacuum chamber is used with continuous antechambers connected to both sides of the beam chamber via slots. Synchrotron radiation dump surfaces and distributed vacuum pumping are located in both antechambers. We describe the design and analysis of the vacuum chamber, dump and magnets.
\end{abstract}

\section{1-INTRODUCTION}

PEP-II B factory LER employs wiggler magnets for beam emittance excitation and synchrotron radiation damping. The beam emittance of this ring without wigglers is only 22 $\mathrm{nm} \cdot \mathrm{rad}$, compared to a nominal design emittance of $64 \mathrm{~nm} \cdot \mathrm{rad}$. Moreover, an emittance variation of $40-100 \mathrm{~nm} \cdot \mathrm{rad}$ is envisaged for LER operation in order to provide flexibility of beta-function adjustments at the interaction point and luminosity optimization. Damping associated with wigglers consists in a reduction of damping time from $64 \mathrm{msec}$ to 47 msec with an energy spread of $8.1 \times 10^{-4}$ in a variant with all wiggler magnets in place. Wiggler magnets are inserted into two LER straight sections with the wiggler centered in a chicane (see Fig. 1). The chicane is formed by four dipole magnets and these chicane bend magnets play an important role in emittance adjustments. By varying the betatron phase advance between pairs of chicane dipole magnets, one can efficiently control excitation of the form factor $H=D_{x}^{2} / \beta_{x}$ given here in the center of the wiggler section. (As usual $D_{x}$ is the dispersion function and $\beta_{x}$ is the horizontal betafunction). If the chicane bends work together with the wiggler magnets, emittance excitation is controlled by the form factor $H$, and the wiggler contribution to overall emittance can be maximized. Fig. 2 shows the behavior of beta-functions and the dispersion function along the wiggler straight section for the nominal $64 \mathrm{~nm} \cdot \mathrm{rad}$ beam emittance case.

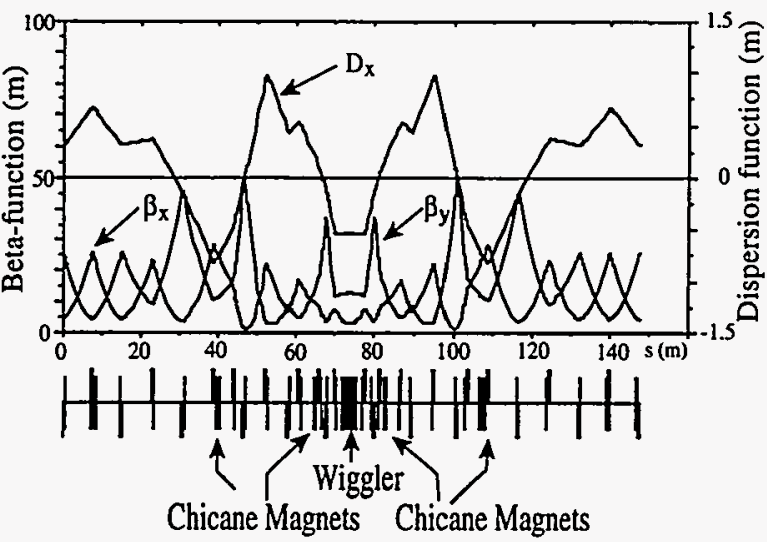

Fig. 2 Wiggler Dispersion and Beta-Functions

\section{2-WIGGLER DESIGN CONCEPT}

Beam lattice layout of both wiggler locations are identical with the circulating beam shifted toward the center of the ring with a chicane as shown in Fig.1. The chicane bend angles were chosen to be the same as the standard LER bend magnets (1.875 degrees) as a cost optimization. The chicane standard bend magnets will be connected in series electrically with the LER dipole string magnets.

The wiggler magnets are conventional water cooled iron core dipole magnets designed to operate at $1.6 \mathrm{~T}$. All wiggler magnets are individual " $\mathrm{H}$ " magnets which are mounted onto a rigid girder located below the magnets. Our wiggler magnet iron core lengths are longer than most wiggler magnets and the wide angle synchrotron radiation fans deposit most of the synchrotron radiation onto the vacuum chamber sidewalls immediately downstream of the wiggler.

The wiggler vacuum chamber is approximately $25 \mathrm{~m}$ long and the material is copper. Synchrotron radiation produced by the wiggler magnets is intercepted by continuous dumps which are an integral part of the copper vacuum chamber sidewall as shown in Fig. 3. Continuous vacuum pumping is also provided on both sides of the vacuum chamber via pumping slots.

Both wiggler chicanes will be installed for start-up, but only one of the wigglers will be installed. A second wiggler will be installed later if necessary.

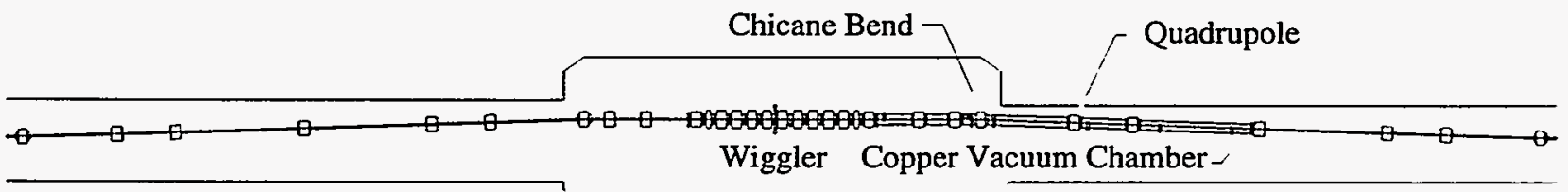

Fig. 1 Wiggler Chicane Layout 


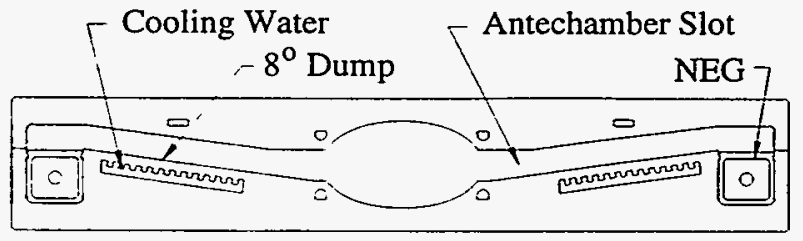

Fig. 3 Wiggler Vacuum Chamber Cross-Section

\section{3-SYNCHROTRON HEATING}

A computer program was written to calculate the magnitude and distribution of the synchrotron radiation (SR) incident upon the dump surfaces downstream of the wiggler. Heat flux distribution across the dump surface was also calculated for the peak heating areas. This heating data was then used as an input for temperature and stress calculations. Synchrotron radiation heating distribution is shown in Fig. 4 with the downstream end of the wiggler shown as the origin. Note that for distances less than $6 \mathrm{~m}$ downstream of the wiggler, the synchrotron radiation is incident upon both sidewalls, and the distributions are shown as solid and dashed curves. For distances greater than $6 \mathrm{~m}$, one of the sidewalls is shadowed by the chicane bend, and only one distribution curve is shown. Also note that the heating increases by more than a factor of three at the chicane bend into the resume line to a peak of approximately $330 \mathrm{~W} / \mathrm{cm}$. The heat flux density at this chicane bend location is approximately $220 \mathrm{~W} / \mathrm{cm}^{2}$, but it is not the peak heat flux. The peak heat flux density of 415 $\mathrm{W} / \mathrm{cm}^{2}$ is located at the highest spike on the sidewall upstream of the bend (see Fig. 4).

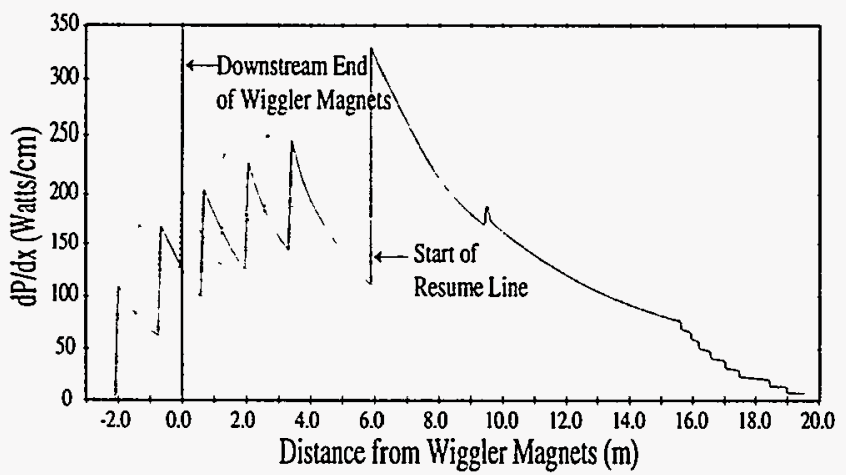

Fig. 4 Synchrotron Heating Distribution

\section{4-VACUUM CHAMBER DESIGN}

The wiggler vacuum chamber consists of a $90 \mathrm{~mm} \times 40 \mathrm{~mm}$ elliptical beam aperture with continuous SR slots on both sides. The SR slots are sloped at $8^{\circ}$ to form water cooled dump surfaces to absorb the SR power. Continuous plenums with distributed Non-evaporable Getter (NEG) pumps are located behind the dump surfaces (See Fig. 3).

The wiggler vacuum chamber top/bottom sections are made from two half-hard C10100 OFHC copper plates which are machined and electron-beam welded together to form the vacuum chamber. After fabrication the chamber will be vacuum baked at $200 \mathrm{C}$ for one to two days and then glowdischarge cleaned using an argon/oxygen gas mixture.

Design of the distributed NEG pumps is an innovative departure from conventional NEG designs. SAES ST707 strip is cut into individual "wafers" and stacked onto a stainless steel tube with $2 \mathrm{~mm}$ spacers between wafers. The stainless steel tube wall serves as both the vacuum barrier and support for the NEG. A commercial heater is inserted into the tube and used to activate the NEG's with the heater outside of the vacuum space, therefore, penetration of the vacuum wall with an electrical feed-thru is not required. With this design feature, a failed heater can be replaced with the chamber under vacuum. Each pump contains 11.4 meters of NEG strip per meter of length. This provides a distributed pumping speed of $400 \mathrm{l} / \mathrm{s} /$ meter of length with a getter capacity of 1.14 Torr1/meter. Estimates show that this pumping capacity should limit NEG pump reactivations to once per year. The distributed NEG pumps will be supplemented by discrete ion pumps to pump hydrogen during NEG activation.

The LER Wiggler has the potential to experience a pressure bump vacuum instability. This phenomenon occurs when beam and photon produced ions get accelerated toward the chamber walls by the 600 volt average beam potential. These ions can desorb up to 10 new gas molecules on impact. If the pumping speed is too low, this new desorbed gas can lead to an avalanche effect and produce a runaway pressure spike, which leads to beam loss. A high pumping speed and wide distribution of the wiggler vacuum system should eliminate beam-induced degassing problems. The positive effect of this phenomenon is to accelerate the clean-up of the vacuum chamber.

Synchrotron radiation from the wiggler poses two problems for the vacuum system. The first problem is the large gas load caused by photo-desorption which must be effectively pumped by the NEG system. The photo-desorption is $5 \times 10^{-6}$ Torr$1 /$ meter. Our beam-line pressure calculations predict an average vacuum pressure of $3.4 \mathrm{nTorr}$. This pressure is well within the design goal of the wiggler vacuum system of 10 nTorr.

The second problem is the thermally induced stresses at the dump surface. A thermal/structural analysis of the vacuum chamber was done using a 2D model and the ANSYS finite element code. A 200 psi cooling water pressure, atmospheric pressure and synchrotron radiation heating were applied simultaneously to the thermal/structural model.Thermal analysis results show peak temperatures of $117 \mathrm{C}$ and $87 \mathrm{C}$ on the dump surface and cooling water channel surface respectively. The cooling water channel surface temperature is well below the coolant boiling point and film boiling will not occur.

The highest thermally induced stress is a compressive stress in the longitudinal/beam direction (a principal stress) and it is due to the localized synchrotron heating. The heated stripe would like to grow longitudinally, but the remainder of the vacuum chamber constrains the growth and compressive stresses develop in the heated area. Similar findings were 
reported by $\mathrm{R}$. Wong [1] and the PEP-II Conceptual Design Report [2]. A peak longitudinal compressive stress of $22 \mathrm{ksi}$ is developed in the highest temperature region. The two remaining principal stresses in this area are small compared to the longitudinal stress and the resultant von Mises stress of 20 ksi is lower than the longitudinal stress. All stresses due to pressure loading are well below the allowable working stress and their contribution to the combined stresses in the heated zone are not significant. An allowable stress of $2 / 3$ yield stress was used as a static allowable stress.

An analysis was also performed to estimate the fatigue failure safety margin. An axial compression cycle is initiated each time the LER is filled with beam and a maximum of 20,000 fills are expected over the life of the machine. We used the copper S/N curves presented in Z. Wangs et al. paper [3] and a maximum operating stress of $22 \mathrm{ksi}$ to estimate the number of cycles to crack initiation as $30 \times 10^{4}$ cycles. The number of crack initiation cycles divided by the number of beam fills gives a crack initiation safety factor of 15 .

We have concluded that the stress behavior of the dump surface is dominated by the principal stress in the longitudinal beam direction and the peak stresses in the heated area may be estimated to good accuracy with temperature information and the simple expression

$\sigma=\alpha \mathrm{E} \Delta \mathrm{T}$, where

$\sigma=$ Peak compressive stress,

$\alpha=$ Expansion coefficient for dump material,

$\mathrm{E}=$ Modulus of Elasticity for dump material,

$\Delta \mathrm{T}=(\mathrm{Tmax}-\mathrm{Tavg})$ for the vacuum chamber cross-section.

\section{6-WIGGLER MAGNET DESIGN}

All wiggler dipole magnets are individual " $\mathrm{H}$ " magnets using laminated iron cores and water cooled aluminum coils. Aluminum was chosen as the conductor material to be compatible with an existing aluminum cooling water system. Magnet coils are layer wound with an even number of layers so that both leads are located on the side of the coil away from the vacuum chamber. The wiggler magnets are connected in series electrically with alternating polarities. The middle dipole magnets are full magnets ( $40 \mathrm{~cm}$ long) while the end magnets are half magnets ( $20 \mathrm{~cm}$ long). Wiggler end magnets have water cooled aluminum trim coils wound onto the outside of the primary windings. The trim coils are sized to provide a horizontal beam adjustment of $\pm 2 \mathrm{mr}$. A wiggler magnet cross-section is shown in Fig. 5.

\section{7-INSTRUMENTATION AND DIAGNOSTICS}

Instrumentation and diagnostics for each wiggler include beam position monitors which feed back to corrector magnets for steering, sets of thermocouples every two meters along the vacuum chamber to protect against overheating, and radiation monitors which serve as a fast-response protection system and provide feedback to vertical correctors which keep the synchrotron radiation fan centered on the dump surface. A possible additional diagnostic is an optical monitor which will show the vertical profile of the scattered light from the synchrotron radiation fan.

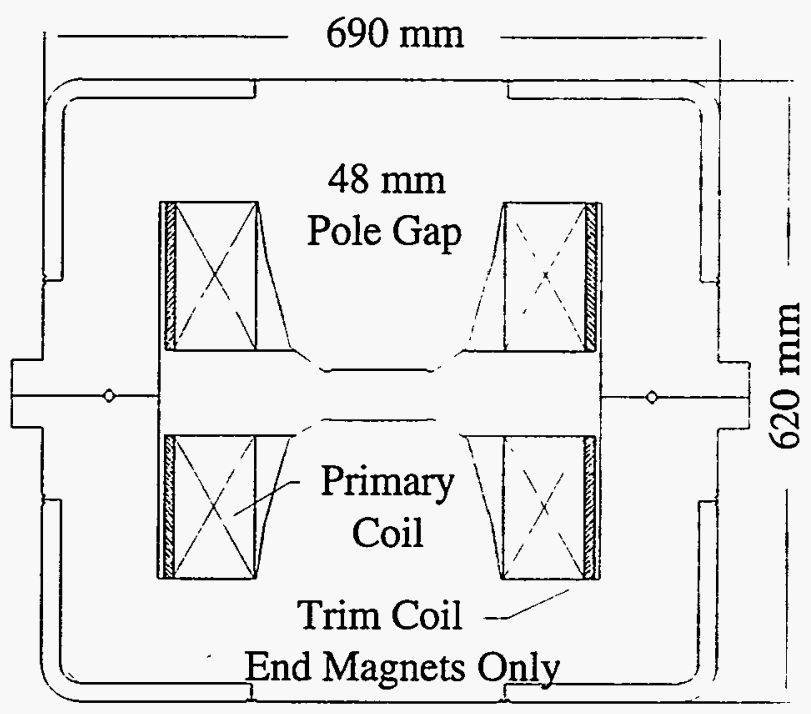

Fig. 5 Wiggler Magnet

\section{8-SUMMARY AND FUTURE PLANS}

The preliminary design/analysis of the wiggler has been completed and detailed design is progressing. We will complete detailed design in 1995 and all fabrication work will be done in 1996. A full size cross section of the vacuum chamber $1.5 \mathrm{~m}$ long is being built as a fabrication prototype, and the prototype fabrication experience will be evaluated as part of the detailed design. A final design review is planned for this summer.

\section{ACKNOWLEDGMENTS}

This work was supported by the Director, Office of Energy Research, Office of High Energy and Nuclear Physics Division, of the U. S. Department of Energy under Contracts DE- AC03- 76SF00098 and W-7405-ENG-48 (LLNL).

\section{REFERENCES}

[1] R. Wong, "B-Factory High-Energy-Ring TwoDimensional Thermal-Stress Analysis", SCMDG 90-5.1-59, LLNL, December 19, 1990.

[2] PEP-II An Asymmetric B Factory, Conceptual Design Report, LBL-PUB-5379, SLAC-418, CALT-68-1869, UCRLID-114055, p 326-330, June 1993.

[3] Z. Wang et al., "Low-cycle-fatigue behavior of copper materials and their use in synchrotron beamline components", Nuclear Instruments \& Methods in Physics Research, Section A 347, p 651-656, 1994. 